\title{
L. Some circumstances relative to Merino sheep, chiefly collected from the Spanish shepherds, who attended those of the flock of Paular, lately presented to his majesty by the government of Spain; with particulars respecting that great national acquisition; and also respecting the sheep of the flock of Negrete, imported from Spain by his majesty in the year 1791
}

\section{Sir Joseph Banks}

To cite this article: Sir Joseph Banks (1809) L. Some circumstances relative to Merino sheep, chiefly collected from the Spanish shepherds, who attended those of the flock of Paular, lately presented to his majesty by the government of Spain; with particulars respecting that great national acquisition; and also respecting the sheep of the flock of Negrete, imported from Spain by his majesty in the year 1791, Philosophical Magazine Series 1, 33:132, 287-290, DOI: $10.1080 / 14786440908562868$

To link to this article: http://dx.doi.org/10.1080/14786440908562868 
L. Some Circumstances relative to Merino Sheep, chiefly collected from the Spanish Shepherds, who attended those of the Flock of Paular, lately presented to His Majesty by the Government of Spain; with Particulars respecting that great National Acquisition; and also respecting the Sheep of the Flock of Negrete, imported from Spain by His Majesty in the Year 1791. By Sir Joseph Banks.

[Concluded from p. 248.]

IN the year 1787 the king, guided by those patriotic motives which are ever active in his majesty's mind, gave orders for the importation of Merino sheep for his own use, and for the improvement of British wool. As it was doubtful at that time whether the king of Spain's license, without which these sheep cannot be embarked at a Spanish port, could be obtained, it was deemed advisable to make the first purchases in the parts of Estremadura adjoining to Portugal, and to ship the sheep for England at Lisbon. The first importation of these valuable animals arrived in March 1788, and a little flock of them was soon after completed; but as these were of various qualities, having been drafted from different Cavañas, his majesty was pleased to order an application to be made to the king of Spain by lord Auckland, then his majesty's minister at that court, for permission to import some sheep drafted from one of the prima piles. This was obtained; and a little flock, consisting of 36 ewes, 4 rams, and 1 manso, arrived safe and well at Dover, in 1791. These sheep had made a part of the Cavana called Negrete, one of the three piles-restricted from exportation, and which is likewise remarkable for producing the largestcarcased sheep that are to be found among the Merino flocks, as has been before stated.

On the receipt of this treasure, (for such it has since proved itself to be,) the king, with his usual prudence and foresight, ordered the whole of the sheep that had been procured by the way of Portugal to be disposed of, (which was immediately done, and directed the Negrete breed to be increased as much as possible, and maintained in its utmost purity. 


\section{Some Circumstances relative to Merino Sheep.}

From that time to the present the opinion of the public, sometimes perhaps too unwary, and at others too cautious, in appreciating the value and adopting the use of novel kinds of sheep, has gradually inclined to give that preference to the Merinos which is so justly their due. At first it was impossible to find a purchaser willing to give even a moderate price either for the sheep or for their wool; the shape of the sheep did not please the graziers, and the wool-staplers were utterly unable to judge of the merit of the wool, it being an article so many times finer and more valuable than any thing of the kind that had ever before passed through their hands. The butchers, however, were less timorous; they readily offered for the shecp, when fat, a fair mutton price; and there are two instances in which, when the fat stock agreed for was exhausted, the butcher who had bought them anxiously inquired for more, because he said the mutton was so very much approved of by his best customers.

It was not, however, till the year 1804, thirteen years after their first introduction, that it was deemed practicable to sell them by auction, the only certain means of placing animals in the hands of those persous who set the highest value upon them, and are consequently the most likely to take proper care of them. The attempt, however, succeeded; and the prices given demonstrated that some at least of his majesty's subjects had at that time learned to put a due value on the benefit his royal patriotism offered to them. One of the rams sold at the first sale for 42 guineas, and two of the ewes for 11 guineas each; the average price at which the rams sold was $19 l .4 s$, and that of the ewes $8 l .15 s .6 d$. each.

This most useful mode of distribution has since that time been annually continued, and the sales have taken place in the beginning of August. The last sale was held on the 17 th of August, 1808, when the highest price given for a ram was $74 l .11 \mathrm{~s}$, for an ewe $38 \mathrm{l}$. $17 \mathrm{~s}$. The average prices of rams was $33 l$. 10s. $1 d$., of ewes $23 l .12 s, 5 d . ;$ - a most decisive proof not only that the flock had risen very materially in public estimation, but also that the sheep have not in any way degenerated from their original excellence. 
The wool was at first found to be quite as difficult of sale as the sheep theraselves; manufacturers were therefore employed to make a considerable quantity of it into cloth, which, when finished, was allowed by both woollen-drapers and tailurs to be quite as good as cloth made of wool imported from Spain. But even this proof would not satisfy the scruples of the wool buvers, or induce them to offer a priçe at all adequate to the real value of the article: it was found necessary, therefore, to have the wool scoured, and to sell it in that state as Spanish wool, which, though grown in England, it really was. Thus managed, the sales were easily effected for some years, at a price equal to that demanded for the prima piles of imported Spanish wool at the times when the bargains were made.

Time and patience have at last superseded all difficulties, and his majesty's wool has now for some years been sold as clipped from the sheep's backs, the sheep having been washed, and the whole management of them carried on exactly in the English manner, at a price not lower than 4.s. $6 d$. a pound, which, allowing for the loss of weight in the scouring, costs the buyer at least $5 s .6 d$. a pound, a tolerable price for Spanish wool when plenty of it could be produced, though not possibly so high an one as ought to have been given or as will be obtained for the Anglo-Negrete pile, when the value of the article is fully understood.

The race of another capital Cavaña has now been added to the riches of this country, the Paular, and the draught from it is larger than on any other occasion has been suffered to leave Spain; the animals have been selected with skill and attention, the pile they belong to stands at the very top of our English list, and the sheep have been most fortunately placed at the disposal of our most gracious king, whose shepherds have demonstrated to the public, in an experience of 17 ycars of their management of these interesting animals, that they can not only continue the breed in its original purity, but can also preclude all danger of degeneration in the article of wool. What more can be wished for on this head?

That spirit of patriotism, which induced our sovereign to Vol. 33. No, 132, April 180 . 
declare himself the protector of the purity of the Negrete race, will also, it is most earnestly to be hoped, induce his majesty to extend the same protection to the newly arrived Paulars ; by this measure, and by this alone, the public will be effectually guarded against all danger of the admission of impure blood, which the avarice of ill-judging individuals, seeking after a premature improvement of the carcase, bas too often, it is feared, introduced into our English flocks. Thus protected, the twofold treasure obtained for the advantage of his subjects by his majesty's wisdom and foresight, will become a perennial fountain of true Merino blood, to which those agriculturists who are wise enough to adopt the breed may from time to time resort, to correct their errors if they fall into bad practices, to carry on their crosses, if any such are found to be advantageous, to the highest degree of perfection, and to restore the originality of their stock, if, in consequence of any unsuccessful experiment, it should have suffered deterioration.

LI. Remarks on M. BuRckHARDT's Contrivance for shortening Reflecting Telescopes; with a new Method of making Refracting Telescopes with a Tube only one-third of the focal Length of the Olject-glass. By David Brewster, LL.D. F.R.S., and F.A.S., Edin.

$\mathrm{I}_{\mathrm{N}}$ the Connaissance des Tems for 1809 , I observe the de-
scription of a new telescope, invented by the celebrated $\mathrm{M}$.
Burckhardt, of an intermediate nature between the Gregorian
and Newtonian telescopes; and requiring a tube only half
as long as other instruments of the same focal length. The
large concave speculum AB, Fig. 1 , (Plate IX.) is perfo-
rated as in the Gregorian telescope, so that the diameter of
the aperture ef may be half the diameter AB. The parallel
rays $\mathrm{R} m, \mathrm{R} n$, which, after reflection, would have formed
the image at $\mathrm{F}$, are intercepted by a plane speculum C, per-
pendicular to the axis of the telescope, and of the same size
as the aperture ef, and are reflected back to the point 0 ,
where 